\title{
ABOCANHANDO O MERCADO: O CASO DA ROCK HAMBURGUERIA
}

SNAPPING UP THE MARKET: THE ROCK HAMBURGUERIA CASE

Recebido em: 05/08/2016 Aprovado em: 11/10/2016

Avaliado pelo sistema double blind review Editora Científica: Claudia Stadtlober DOI 10.13058/raep.2017.v18n1.471

\author{
ANA PAULA KIELING anakieling@gmail.com \\ ESTELAMARIA HOFFMANN \\ UNIVERSIDADE DO VALE DO ITAJAÍ \\ RICARDO BOEING \\ UNIVERSITY OF WISCONSIN
}

\section{RESUMO}

O presente caso de ensino objetiva oportunizar aos alunos a vivência de situações pertinentes ao contexto mercadológico a partir da análise da gestão da Rock Hamburgueria, um estabelecimento que vende hambúrgueres gourmet em um ambiente competitivo. O restaurante, aberto em 2014 em Florianópolis-SC, pelos sócios Melissa Andrade e André Fernandes, obteve retorno em seu primeiro ano de atividades, mas tem sofrido uma queda nas vendas, atribuída ao aumento da concorrência no setor no período e à crise econômica enfrentada no país. Para diferenciar-se dos demais, há a necessidade de investimento em estratégias de marketing; e, frente ao capital limitado para investir na área, os sócios deparam-se com um dilema para atingir seu público-alvo em busca de melhores resultados: manter o foco em ações de marketing tradicional ou de marketing digital? Como instrumento de ensino, o caso foi desenvolvido para uso em cursos de graduação e pós-graduação em Administração de Empresas e Marketing. O debate inclui temas como administração de marketing e marketing digital nas disciplinas de Administração Mercadológica e Marketing Digital.

Palavras-chave: Administração de Marketing; Marketing Digital; Estratégias de Marketing; Caso para Ensino.

\begin{abstract}
This study case aims to offer the students an opportunity of experiencing relevant situations to the marketing context, from the management analysis of Rock Hamburgueria, an establishment that sells gourmet burgers in a competitive environment. The restaurant, opened in 2014 in Florianópolis, SC, Brazil by Melissa Andrade and André Fernandes, was profitable in its first year of activity, but has suffered a drop in sales, attributed to the increased competition in the industry and the economic crisis in the country. To outstand from the others, reach their target audience and achieve better results, the partners need to invest in marketing strategies, but given their limited capital to invest in the field, the partners are facing a dilemma: should they focus on traditional marketing or digital marketing actions? As a teaching tool, the case was developed to be used in graduate and undergraduate courses in Business Administration and Marketing. The discussion in the in Marketing Management and Digital Marketing courses includes topics such as marketing management and digital marketing.

Keywords: Marketing Management; Digital Marketing; Marketing Strategy; Case Study.
\end{abstract}




\section{INTRODUÇÃO}

No final de 2014, o cenário gastronômico de Florianópolis vivenciou um boom na abertura de estabelecimentos do ramo de comida de rua, tais como food trucks e hamburguerias. O consumo de hambúrguer estava em expansão no Brasil naquele momento, sendo considerado uma tendência em outras grandes cidades como Rio de Janeiro e São Paulo, onde um hambúrguer chegava a ser vendido por até $300 \%$ do seu custo de produção, segundo reportagem da Folha de São Paulo (2014). Nesse contexto, entretanto, a economia brasileira começava a dar sinais de retração.

Meses antes, dois amigos uniram-se como sócios para abrir um restaurante com conceito de hamburgueria gourmet. Era fevereiro de 2014 e, na data, apenas dois outros restaurantes trabalhavam especificamente com venda de hambúrgueres na capital.

Os sócios, Melissa Andrade e André Fernandes, haviam sido colegas no curso de Administração há alguns anos e reencontraram-se em um curso em 2012, quando retomaram o contato. Desde então, os jovens discutiam a possibilidade de abrir uma empresa juntos e, após uma pesquisa de mercado, decidiram investir suas economias na abertura de um restaurante, no início de 2014, a Rock Hamburgueria.

Embora o começo das atividades tenha sucedido de maneira positiva, com o passar dos meses, houve uma queda no fluxo de clientes e as vendas diminuíram consideravelmente. No início - no auge do negócio -, o faturamento médio mensal era de R $\$ 70$ mil reais. Após a entrada de novos concorrentes e a queda no movimento devido à crise econômica que se instalou no país, Melissa e André viram seu faturamento reduzir em $20 \%$, comprometendo o bom andamento do negócio. Em uma manhã fria de inverno, acreditando na força das estratégias de marketing para retomar os bons resultados da hamburgueria, os dois discutiam sobre qual seria a melhor forma de investimento mercadológico: manter o foco em ações de marketing tradicional ou de marketing digital? 


\section{A IDEIA}

Atentos aos movimentos do mercado na capital catarinense, no início de 2014, os empreendedores Melissa Andrade e André Fernandes decidiram abrir um restaurante que oferecesse opções de hambúrguer gourmet em Florianópolis. O comércio de hambúrguer gourmet estava em expansão naquele momento, sendo considerado uma tendência em outras grandes cidades. No entanto, em Florianópolis, a cidade contava com apenas dois estabelecimentos do gênero, assim, os dois amigos detectaram uma oportunidade de investimento na região.

Na gastronomia, o termo gourmet é comumente atribuído a experiências alimentares mais elaboradas, com a utilização de produtos de alta qualidade para a execução dos pratos. Com base nesse conceito, a ideia dos sócios era oferecer lanches rápidos, mas de qualidade, em um ambiente simples, porém agradável. Ao contrário dos outros dois estabelecimentos que existiam na cidade, que se destacavam por uma decoração sofisticada em locais de grande fluxo de pessoas, a Rock Hamburgueria diferenciava-se pelo sabor de seus produtos e pela garantia de oferecer aos clientes preços menores que os da concorrência, um privilégio que o baixo investimento envolvido em estrutura permitia aos donos flexibilizar, em um primeiro momento.

Em poucas semanas, o estabelecimento já contava com bom movimento graças ao seu diferencial, e os idealizadores da ideia pareciam satisfeitos com o retorno do negócio.

\section{COMO TUDO COMEÇOU}

Melissa e André eram bons amigos desde a faculdade. Os dois cursaram Administração na mesma turma e sempre tiveram o apoio da família e de professores para investir em projetos e empreender. A dupla esteve envolvida com diversas ações empreendedoras ao longo da trajetória acadêmica, entretanto, após o fim das aulas, seu relacionamento era apenas de amizade.

Um dia, em setembro de 2013, Melissa e seu esposo, Rodrigo, promoveram um jantar em sua casa, onde receberam André e sua esposa, Gio- 
vana. Na ocasião, a conversa fluía e, assim, surgiu a oportunidade de uma parceria:

- André, você ouviu falar da "onda gourmet" que vem tomando os restaurantes do Brasil? Estava lendo sobre isso na internet essa semana.

- Para falar a verdade, sim! Estes dias eu e a Giovana fomos surpreendidos com um hambúrguer gourmet na Via Gastronômica. O local está super badalado e o ambiente é agradável.

- Ah, é? Eu e o Rodrigo ainda não fomos conhecer, mas ouvi falar. E a comida é boa?

- Então, como eu ia dizendo, o ambiente é bacana, mas o hambúrguer não é grande coisa. É hambúrguer, né? Pão, carne, iguarias. Nada espetacular!

- E o preço?

- Achei caro! R\$32,00 por um hambúrguer, já pensou? Os donos devem estar ricos, porque tinha fila para entrar.

Melissa pareceu espantada com o que André falou; e Giovana complementou:

- Vocês não imaginam a fila. Achei que ia comer um hambúrguer de ouro! Eu adoro hambúrguer, mas também não achei incrível. É apenas "ok".

- Que coisa! Caro mesmo... aposto que a conta não foi barata. E dá para ver que a fama da hamburgueria vem atrás do título "gourmet", não é? - disse Rodrigo.

André respondeu, fazendo cara feia:

- Rodrigo, acredite, a conta saiu mais de $\mathrm{R} \$ 100,00$ por dois hambúrgueres, batatas e dois chopes.

Animada, Melissa, então, deu uma ideia:

- Podíamos tirar aquela nossa ideia do papel, André. Lembra como sonhávamos em abrir uma empresa na época da faculdade? Parece uma oportunidade!

- Melissa, sabe que não é má ideia? Não vejo muitos concorrentes e o setor parece promissor. A cidade está carente de novidades em termos de gastronomia. 
Rodrigo apoiou os amigos:

- Parece interessante! Essa vontade de vocês de empreender já é antiga mesmo. Por que não investem em uma pesquisa de mercado e vão em frente? Dou o maior apoio.

Empolgados com a ideia, os quatro amigos brindaram com vinho e, a partir deste dia, Melissa e André concentraram seus esforços em implantar o novo negócio.

\section{EM BUSCA DE SABOR}

Por mais que os sócios tivessem conhecimentos em gestão, abrir um negócio não foi fácil. Exigiu muita dedicação dos dois, desde os primeiros esforços, com a elaboração do plano de negócios e aplicação de pesquisa de mercado, passando pelo investimento financeiro, a seleção de pessoal, a qualificação da equipe, até a montagem da estrutura física.

Os esforços em pesquisa de mercado mostraram que havia espaço para crescer e que apenas dois restaurantes eram concorrentes diretos no negócio de hamburguerias na cidade. Na percepção dos sócios, a grande oportunidade estava em oferecer lanches saborosos e, se possível, a preços módicos.

Após muitas projeções, cálculos e busca pelos fornecedores certos, em abril de 2014, nascia a Rock Hamburgueria, em um local próximo à Via Gastronômica da cidade, com espaço para atender até 36 clientes por vez, em oito mesas simples, sem sofisticação, mas oferecendo cinco tipos de hambúrguer (picanha, costela, linguiça Blumenau, frango e a versão vegetariana, de soja), três tipos de acompanhamento (batatas fritas, batatas rústicas e anéis de cebola fritos) e quatro tipos de bebida (refrigerante, água, suco em lata e cerveja). Os preços dos produtos eram fixos, sem nenhum tipo de promoção, nem mesmo durante os dias de semana.

A equipe contava com dois garçons, um cozinheiro, dois assistentes de cozinha, uma faxineira e a dupla, esta responsável por administrar o negócio. Como os dois sempre estavam no estabelecimento, era comum vê-los circulando entre os clientes para checar como andava o serviço e, em dias de maior movimento, ajudando a servir os lanches. 
A escolha de Melissa e André parecia acertada: semana após semana, recebiam elogios pelo gosto único dos produtos oferecidos, e a casa estava sempre cheia. Em alguns dias, como fim de semana, pequenas filas formavam-se na rua. Todos queriam experimentar o hambúrguer simples, mas delicioso, que o local oferecia. Eles estavam provando o que queriam: que não precisavam de um ambiente chique para manter um negócio gourmet, pois o que vendia mesmo era o sabor.

\section{CHUVA DE HAMBÚRGUERES}

Após seis meses da abertura, a Rock Hamburgueria continuava dando bons resultados a seus sócios, mas o mercado parecia se movimentar. Em pouco tempo, outros investidores parecem ter percebido o apelo do negócio gourmet e estabelecimentos do gênero começaram a aparecer em outros locais da cidade.

Os hambúrgueres de Melissa e André custavam cerca de 20\% menos do valor cobrado pela concorrência e sua qualidade era equivalente. Mesmo com o apelo do preço inferior, a oferta exagerada de restaurantes da região fez com que as filas frequentes cessassem e, durante a semana, várias mesas acabavam vazias. A concorrência era tanta que, no mesmo bairro da Rock, outras três hamburguerias abriram no período. O faturamento médio mensal estava cada vez menor, e os gastos com os funcionários, a manutenção do estoque e os encargos tributários prejudicavam o andamento do negócio. $\mathrm{O}$ aumento da concorrência e a crise econômica no país agravaram a situação.

Era início de setembro e, atipicamente, chovia em Florianópolis. Os sócios estavam reunidos em uma das mesas do restaurante, em uma segunda-feira, dia em que o estabelecimento fecha as portas para manutenção e folga dos funcionários.

- Parece que está "chovendo" hambúrguer nessa cidade, nunca vi coisa igual! - disse Melissa, visivelmente chateada.

- É verdade. Nosso movimento caiu consideravelmente. Estou revisando as finanças e já dá para ver que, se as coisas não melhorarem, vamos ter que fechar - respondeu André, desolado. E continuou: 
- Não é justo subirmos o preço dos produtos porque não temos mais um grande número de clientes. Isso só vai fazer as coisas piorarem. Demitir funcionários também parece precipitado. Temos que pensar em alguma coisa, mudar o posicionamento, rever as estratégias.

- Vou conversar com o Rodrigo hoje à noite e, amanhã, nos reunimos novamente. Você está certo: é hora de tomarmos decisões e partirmos para a ação. Queríamos tanto esse negócio! Investimos tanto! Nem pense em fechar, vamos encontrar uma solução - afirmou Melissa.

\section{Análise do Mercado}

À noite, Melissa expôs a situação a seu marido, que trabalhava como gerente de marketing em uma agência de publicidade. Os dois falaram sobre as ações de marketing e comunicação que haviam sido feitas até então e buscaram avaliar o retorno financeiro delas. Após uma breve análise, perceberam que a Rock Hamburgueria não havia investido muito em estratégias de marketing ao longo do tempo: apenas a distribuição de dois mil panfletos no primeiro mês de funcionamento ( $\mathrm{R} \$ 250,00)$, no bairro e em frente à universidade, além de 20 inserções de anúncios de 30 segundos na rádio local ( $\mathrm{R} \$ 400,00)$, com abrangência de 10 mil ouvintes; e a criação de uma fanpage, administrada por eles, na rede social Facebook, que era pouco atualizada e feita de forma informal, sem apoio profissional, contava com 300 seguidores. Além disso, como a dupla confiava no produto, o boca a boca do público satisfeito sempre ajudou a manter e captar clientes, vide quadro 1.

Quadro 1 Investimento Inicial em Marketing da Rock Hamburgueria

\begin{tabular}{|ccc|}
\hline MídiA & AUdi ÊNCIA & VALOR \\
\hline Panfletos & 2 mil & $\mathrm{R} \$ 250,00$ \\
Anúncio na Rádio & 10 mil & $\mathrm{R} \$ 400,00$ \\
Facebook & 300 seguidores & - \\
\hline
\end{tabular}


Com isso em mente, Melissa e seu marido, na busca por opções para alavancar a hamburgueria, começaram traçando o público-alvo do negócio, no caso, jovens durante a semana, devido ao movimento da universidade na região, e famílias pequenas aos fins de semana, por se tratar de um bairro residencial.

Outro tópico da conversa foi a lista dos produtos mais consumidos pelos clientes da casa. A partir dos relatórios de venda emitidos pelo sistema de computador utilizado pela Rock Hamburgueria, ficava claro que o hambúrguer de picanha era o mais vendido e também o mais procurado pelo público masculino. Nos dias de semana, o hambúrguer de frango obtinha maior destaque, sendo, na maioria das vezes, escolhido por mulheres. Os acompanhamentos variavam bastante, mas as batatas tradicionais eram mesmo as preferidas. Quanto a bebidas, as preferências mostravam que a melhor opção era suco, para o público feminino, e cerveja, para o masculino.

Ao analisar a concorrência local, que era de dois restaurantes que já existiam antes mesmo deles abrirem o negócio e outras três hamburguerias que abriram posteriormente, concluíram que nenhum deles trabalhava com ações promocionais. As concorrentes trabalhavam com um cardápio mais variado, porém a qualidade era inferior, enquanto que a Rock Hamburgueria buscava aperfeiçoar o sabor de seus acompanhamentos e molhos. Outra vantagem da Rock Hamburgueria é que ela possuía fornecedores exclusivos, em locais próximos ao estabelecimento, com produtos frescos e que, consequentemente, refletiam na qualidade dos hambúrgueres servidos.

Os investimentos de marketing e divulgação da concorrência eram em panfletos nos arredores do negócio, principalmente, próximo à universidade. Além disso, uma das hamburguerias investiu em um outdoor próximo à saída do campus. Alguns investimentos esporádicos em datas especiais eram realizados por alguns deles, em jornais locais, mas notou-se que não havia um planejamento de mídia e, especialmente, que este não era o foco da concorrência. As redes sociais também eram utilizadas, e notava-se que havia pouco engajamento do público. 
No caso da Rock Hamburgueria, os investimentos em mídias tradicionais, como rádio e divulgação por meio de panfletos, foram as principais ações tomadas até então. O público do bairro era familiar e essas ações funcionavam para eles. Os estudantes universitários, como sempre passavam por ali, acabaram conhecendo o local e, com isso, também, traziam alguns fregueses. As mídias digitais estavam representadas por meio do Facebook, que não era atualizado com frequência e contava com apenas 300 seguidores.

Assim, trocando ideias sobre as informações encontradas, rabiscaram uma proposta para ser compartilhada com André, no dia seguinte.

\section{E AGORA?}

Melissa havia marcado de encontrar André às 9 horas na Rock Hamburgueria e lá estava no horário combinado. Como o restaurante só abria às 18 horas, eles costumavam fazer reuniões administrativas no mesmo espaço. Com alguns minutos de atraso, André chegou ao estabelecimento, ainda chateado:

- E, então, falou com o Rodrigo? Alguma ideia? Estou péssimo, passei a noite em claro...

- Sim, conversamos. Você sabe como é o Rodrigo, sempre puxa para o lado dele, mas dessa vez penso que o que ele sugeriu tem tudo que ver com a nossa situação. Como ele conhece bastante de marketing, me ajudou a analisar os concorrentes e está certo de que precisamos investir nesta área para oferecer um diferencial.

- Será? Pra mim, é novidade. Sempre funcionamos bem no boca a boca, Melissa. O fato de termos um preço amigável e sanduíches saborosos serviu bem de propaganda desde o princípio, você não acha?

- Acho, mas agora a situação é outra. Temos novos concorrentes, André. Não dá mais pra confiar que o produto vai se vender sozinho.

- E o dinheiro, vamos tirar de onde? Você sabe que as vendas caíram nos últimos meses, Mel. Não podemos errar nos investimentos. Rádio, outdoors... essas coisas de divulgação são sempre caras. 
- André, temos muitos canais para promover o nosso negócio, nem todos eles precisam de grande investimento. A questão é organizar e planejar tudo, e, principalmente, entender onde está o nosso público-alvo e o que ele espera da gente, entendeu? Além disso, esqueceu que hoje em dia existem estratégias modernas e com baixo custo no marketing?

- Entendi, só acho que a gente não pensou muito sobre isso antes.

- Sim, mas é que o nosso produto se vendia por si só, era novidade e havia pouca concorrência, mas agora é preciso buscar um diferencial e ampliar nosso público-alvo. E ainda temos a sorte de ter um profissional da área ao nosso lado para nos ajudar, André.

- Você está com o discurso afiado, hein? Parece que a "aula" de marketing com o Rodrigo foi boa mesmo. Estou curioso para saber qual é o plano...

- Primeiro, precisamos parar e pensar em alguns fatores para, então, decidirmos quais medidas tomar, mas penso que podemos trabalhar com mídia digital, redes sociais e investir no relacionamento com o público jovem, que é mais antenado a essas coisas.

- Ok, Melissa. Concordo contigo que é um público recorrente na Rock. Só acho que não tem como esquecer que alguns de nossos clientes não são tão conectados às tecnologias. Além disso, a divulgação por meio de panfletos e os spots de rádio deram retorno no início. Na minha opinião, devemos retomar essa estratégia e investir em televisão e em anúncios em jornais, afinal, por meio desses canais tradicionais, expandimos nossa clientela. São mídias de massa às quais todo mundo tem acesso.

- André, entendo seu ponto de vista, mas acredito que devemos abandonar totalmente as mídias tradicionais e investir só no campo digital. Instagram, Twitter, Snapchat, Facebook... há uma infinidade de canais que podemos nos relacionar com o público da Rock, principalmente, com os acadêmicos que frequentam a universidade aqui perto.

- Verdade, mas temo que a gente deixe de anunciar em uma grande mídia, como a televisão, e, com isso, não tenhamos tanta visibilidade quanto gostaríamos. 
Nesse impasse, a conversa dos sócios estendeu-se até a tarde naquela terça-feira do início de setembro, marcando não só um novo dia, mas um novo começo para a Rock Hamburgueria. Qual o melhor caminho a seguir: investir no marketing tradicional ou no marketing digital? Era hora de Melissa e André unirem-se para decidir quais estratégias deveriam implantar e, assim, concentrarem seus esforços no mais importante: recuperar sua posição de destaque entre as hamburguerias da região. 


\section{NOTAS DE ENSINO}

\section{OBJETIVOS EDUCACIONAIS}

Este caso, que retrata um novo empreendimento no setor de gastronomia em busca de diferenciação frente a seus concorrentes por meio de estratégias de marketing, tem por objetivo oferecer aos alunos vivência nas situações relacionadas a escolhas entre ações de marketing tradicional e digital para manter-se como destaque em seu segmento. A proposta é fazer com que os estudantes se coloquem na posição de proprietários de um pequeno negócio para interpretar o dilema e, a partir disso, apresentar estratégias possíveis para a obtenção de melhores resultados para a empresa.

\section{UTILIZAÇÃO RECOMENDADA}

O caso foi desenvolvido para aplicação como instrumento de ensino em cursos de Graduação e Pós-Graduação em Administração de Empresas e Marketing, quando do debate de temas como administração de marketing e marketing digital em disciplinas como Administração Mercadológica e Marketing Digital.

\section{FONTES DE DADOS}

A construção do caso foi baseada em informações primárias obtidas por meio de entrevista semiestruturada com um proprietário de hamburgueria, de forma complementar, pela análise de dados secundários provenientes de fontes como páginas de restaurantes do gênero nas redes sociais e artigos relacionados ao setor publicados na internet. A narrativa foi desenvolvida para estruturar o caso e é fictícia, bem como a empresa e os personagens citados no trabalho.

\section{RELEVÂNCIA DO CASO}

Compreender as situações vivenciadas por gestores de negócios é essencial para a formação de profissionais na área de Administração e Marketing devido aos desafios que os atores desses empreendimentos enfrentam em suas atividades corporativas. A abertura de empresas como a Rock Ham- 
burgueria tornou-se comum no cenário atual e, por isso, a capacidade de analisar os obstáculos que surgem ao gerir um negócio e suas relações com as ações de marketing se fazem necessárias. Habilitar estudantes da área à solução de problemas relacionados ao mercado permite o desenvolvimento de princípios de marketing e a compreensão das diferenças entre o marketing tradicional e digital, além da ampliação de competências no que diz respeito à tomada de decisão, à análise dos concorrentes e ao foco em inovação nos negócios.

\section{TÓPICOS PEDAGÓGICOS}

Sugere-se, como organização da aplicação do caso para ensino em questão, a seguinte estrutura:

a. Leitura e análise individual realizada pelos alunos antes da aula.

b. Divisão da turma em equipes, formadas por pequenos grupos, para análise e discussão do caso e das questões propostas (tempo sugerido: 50 minutos).

c. Apresentação das análises elaboradas pelos grupos em painéis de apresentação, estimulando a competição entre as equipes (tempo sugerido: 50 minutos).

d. Discussão das análises em mesa-redonda, facilitada pelo professor da disciplina (tempo sugerido: 30 minutos).

e. Encerramento da mesa-redonda com a votação dos alunos para eleger a equipe que apresentou melhores análises e soluções para o caso, com premiação a ser definida pelo professor (tempo sugerido: 20 minutos).

\section{QUESTÕES PARA DISCUSSÃO E ANÁLISE DO CASO}

As questões foram desenvolvidas visando estimular a reflexão dos estudantes, de forma a melhor estruturar o problema e produzir uma resposta mais analítica do que descritiva. Os questionamentos foram estruturados para que o aluno, primeiramente, identifique a necessidade de inovação e, em seguida, realize uma análise mercadológica da empresa por meio dos 
4Ps. Na sequência, permite-se a elaboração de estratégias considerando a análise prévia e retomando o debate do dilema do caso: concentrar os investimentos em mídias tradicionais ou em mídias digitais? Reforça-se que a possibilidade de utilizar as duas formas de marketing é aceita, uma vez que os aspectos principais são o debate e a argumentação utilizada para defender a estratégia escolhida. Por fim, destacam-se as estratégias de marketing de relacionamento, buscando que o aluno reflita sobre os objetivos das ações realizadas até então. Dessa forma, o aluno está habilitado a construir o conhecimento a partir de um raciocínio amplo e integrado. Para tal, são sugeridas as seguintes questões e, de forma complementar, respostas que apoiam o professor na resolução do caso:

\section{ANÁLISE DO CASO E RELAÇÕES COM A LITERATURA}

A abordagem do presente caso para ensino trata de temáticas como administração de marketing, marketing digital e inovação. Sugerem-se as seguintes respostas para a resolução das questões propostas.

\section{André e Melissa são sócios no ramo da gastronomia e enfrentam uma situação crítica em seu negócio. A hamburgueria, diante da queda nas vendas, necessita inovar em sua forma de gerir o negócio e considerar as mudanças que ocorrem dentro e fora da empresa. Diante disso, de que forma um gestor pode inovar em suas atividades?}

Abrir um novo negócio é sempre um desafio, e, neste caso, o cenário não poderia ser diferente. Segundo pesquisa realizada pelo SEBRAE (2015), em 2014, ano de surgimento da Rock Hamburgueria, houve um aumento de $3,7 \%$ nas iniciativas empreendedoras em relação ao ano anterior, na região Sul do Brasil, onde o empreendimento está instalado. Esses números reafirmam o fato de Melissa e André estarem em um ambiente que estimula a criação de novas oportunidades de empreender. Luthans (2000) afirma que o ambiente é um fator inicial importante como influenciador da estratégia, da estrutura e dos processos de qualquer novo empreendimento. 
Entretanto percebe-se que o estabelecimento do restaurante em um ambiente favorável ao empreendedorismo não foi o suficiente para manter o negócio. Na percepção de Drucker (1985), um empreendedor é aquele que procura por mudanças e desafios, respondendo-lhes de forma inovadora e explorando-os como oportunidades. O contexto disposto pelo caso de ensino mostra que os sócios pertencem a esse perfil, pois, dada a situação crítica vivenciada pela empresa que criaram há seis meses, decidiram ir atrás de soluções.

Em seu trabalho, o autor sugere sete fontes de oportunidade de inovação que podem ser aplicadas pela dupla para reverter o quadro da hamburgueria, considerando 1) mudanças dentro da empresa ou indústria e 2) mudanças fora da empresa ou indústria. Considerando essas fontes, é possível sugerir caminhos para que a Rock Hamburgueria se reestabeleça no mercado gastronômico de Florianópolis e região.

Figura 1 As Sete Fontes de Oportunidade de Inovação
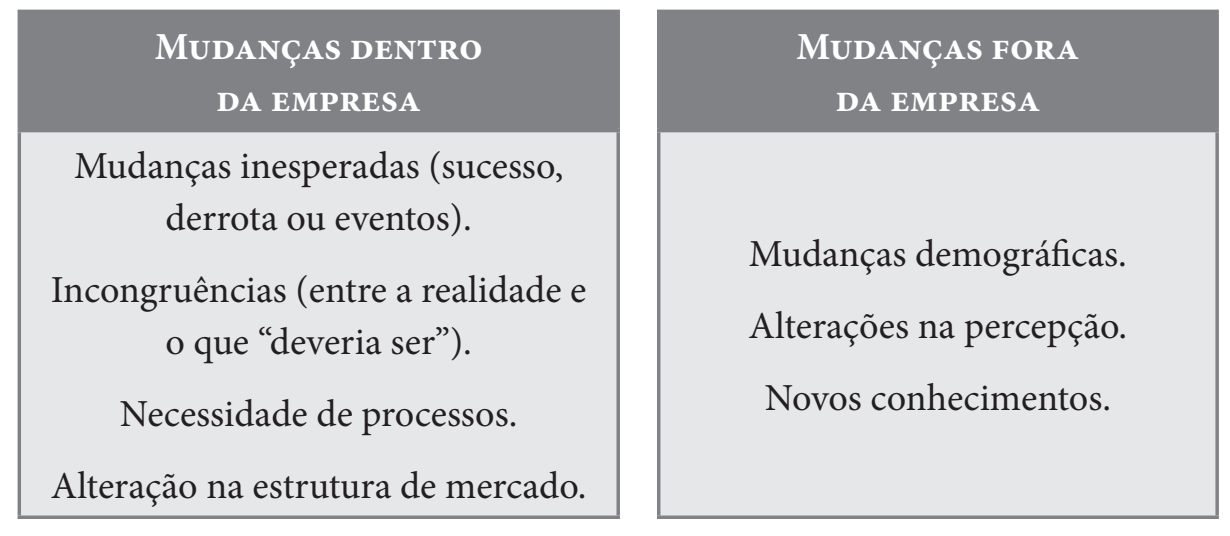

Análise das fontes de inovação a partir de mudanças internas à empresa Ao compreender as fontes de inovação provenientes de mudanças internas à empresa, detecta-se como mudança inesperada o aspecto de que os números da empresa, que a princípio eram positivos, começaram a cair com o tempo. A partir de uma espécie de "derrota" vivenciada pelos empreendedores, surge a oportunidade de buscar por novas formas de desenvolver a 
empresa e prospectar novos clientes, no caso, as estratégias alicerçadas por Melissa e André no que diz respeito a esforços em marketing.

No contexto do caso, existe, também, a incongruência entre o que era esperado pelos sócios (altas vendas e sucesso) e a realidade, que representa baixa popularidade da hamburgueria na região. Essa situação também oferece chances de os sócios inovarem, focalizando nos pontos fortes da empresa, no caso, qualidade e preço acessível.

Outra fonte interna de inovação que permite a mudança é a avaliação das necessidades de processos. A partir do reconhecimento detalhado da cadeia produtiva no estabelecimento, os empreendedores podem reduzir custos desde fornecedores até linha de produção.

Ainda quanto a mudanças internas, a fragilidade do setor ficou exposta mediante a alteração na estrutura de mercado vivenciada por André e Melissa. A Rock, uma das pioneiras no negócio de hamburguerias gourmet na cidade, passou a ser apenas mais uma em apenas meio ano. O que seria o motivo da falência do empreendimento pode ser visto como oportunidade na busca pela diferenciação da marca e do produto.

\section{ANÁLISE DAS FONTES DE INOVAÇÃO A PARTIR DE MUDANÇAS INTERNAS À EMPRESA}

No caso estudado, poucas mudanças demográficas são retratadas, embora esse item também possa ser visto como uma oportunidade de inovação pela empresa. Tendo em vista essa fonte, sugere-se utilizar os dados demográficos provenientes de pesquisas de satisfação e dos sistemas de informação presentes na Rock Hamburgueria em prol do atingimento de resultados.

As alterações de percepção são necessárias para que a empresa volte a crescer, a começar pelo sócio André, que, até então, não julgava importante fazer investimentos na área de marketing. Ao direcionar seus esforços para essa área, a dupla trabalha para transformar a situação crítica em oportunidade.

Por fim, assume-se que a aquisição de novos conhecimentos sobre o mercado e a concorrência, bem como sobre ferramentas que possam 
impulsionar os negócios, tende a desenvolver o negócio. Empreendedores devem estar atentos aos movimentos do setor, sempre, buscando informações atualizadas por meio de sites, livros, revistas e até mesmo periódicos científicos.

2. A Rock Hamburgueria decidiu inovar com foco em esforços de marketing. Apresente os 4Ps do estabelecimento e, levando em consideração os pontos fortes e fracos descritos no caso, desenvolva um plano com ações de marketing a ser implantado pelos sócios nos próximos três meses. Considere um orçamento de $\mathrm{R} \$ 7,5$ mil reais mensais para ser investido em comunicação de marketing.

Os ambientes turbulentos, a diversidade, a complexidade e o dinamismo do mercado são tratados, por Morris (1987), como influências causais no desempenho da organização, sendo função da organização a capacidade de se adaptar a esses fatores. A adaptação estratégica de pequenas empresas refere-se a modificações nos elementos que constituem o núcleo dos seus negócios (SCHINDEHUTTE; MORRIS, 2001). Essa adaptação pode interferir no produto ou serviço ofertado, no perfil do consumidor, no marketing e em tantos outros aspectos. Ela é, portanto, essencial para a sobrevivência do negócio e está diretamente ligada às estratégias de marketing.

Honorato (2003) assevera que os consumidores não compram coisas, e sim soluções para os seus problemas e, por isso, o marketing busca atender a essas necessidades por meio de ações mercadológicas reunidas no chamado Mix de Marketing. O Mix de Marketing foi criado, em 1960, por Jerome McCarthy, que definiu o composto formado por 4Ps: preço, praça, produto e promoção. Estes fatores estão interligados e um exerce influência sobre o outro. Churchill e Peter (2005, p. 20) definem composto de marketing como "uma combinação de ferramentas estratégicas usadas para criar valor para os clientes e alcançar os objetivos da organização".

Conforme Honorato (2003), as definições dos 4Ps de Marketing são as seguintes: 
- O preço é o único componente do Mix de Marketing que gera receita, tendo papel fundamental na participação de mercado da empresa, bem como a sua rentabilidade. Ele envolve, além do preço do produto, as margens de lucro, os descontos, os prazos de pagamento e as condições de crédito.

- A praça refere-se ao local onde acontece o processo de compra e venda dos produtos. Relacionadas a esse ponto estão todas as questões que envolvem a logística e distribuição do produto: os canais, a cobertura/abrangência, o transporte, o armazenamento, o estoque.

- O produto envolve tudo o que possa ser oferecido ao mercado, tanto em mercadoria como prestação de serviço. Esse fator inclui a qualidade do produto/serviço, a variedade, as opções, os estilos, as marcas, as embalagens, etc.

- A promoção diz respeito às ações que divulgam o produto ou serviço. A ela estão ligadas a publicidade, a propaganda, a promoção de vendas, o merchandising, a venda pessoal, etc.

As variáveis relacionadas ao mix de marketing e à inovação são essenciais para o estabelecimento de objetivos que irão compor as estratégias, tendo em vista que essas duas áreas possuem papel importante na obtenção dos resultados pelas empresas (DRUCKER, 1975).

Dessa forma, apresenta-se os $4 \mathrm{Ps}$ do composto de marketing, considerando seus pontos fortes e fracos e, na sequência, algumas estratégias desenvolvidas com base na análise estão dispostas no quadro 2 : 
Quadro 2 Análise dos 4Ps da Rock Hamburgueria

\begin{tabular}{|ccccc}
\hline PREÇO & PRAÇA & PRODUTO & Promoção \\
Análise da equipe: & Análise da equipe: & Análise da equipe: & Análise da equipe: \\
O preço dos ham- & O estabelecimento & O ponto forte da & Como o estabele- \\
búrgueres é um & encontra-se em & Rock é a quali- & cimento surgiu em \\
dos diferenciais & um local simples, & dade e o sabor & um momento que \\
da hamburgue- & mas de bom gosto. & dos seus pratos. & estava na "moda", \\
ria, porém novos & No início das ati- & O fornecedor ex- & o processo de \\
concorrentes sur- & vidades, não havia & clusivo e próximo & promoção ocorreu \\
giram em pouco & muita concorrên- & ao empreendi- & por meio do boca \\
tempo e estão & cia nas redonde- & mento é outro & a boca e por algu- \\
prejudicando o & zas, o que era um & diferencial. Além & mas ações isoladas \\
desempenho do & ponto forte da & disso, o cardápio & de divulgação nos \\
estabelecimen- & hamburgueria, & oferece variedades & meios de comuni- \\
to. Entretanto, & mas infelizmente & que agradam até & cação da cidade. \\
as outras ham- & este quadro foi & mesmo o público & Anúncios na rá- \\
burguerias não & modificado. Estu- & vegano. No en- & dio, distribuição \\
investem tanto & dantes universitá- & tanto, parece que & de panfletos e a \\
em qualidade da & rios e moradores & esse diferencial & página do Face- \\
matéria-prima. & do bairro são o & não estava sendo & book estavam \\
& público principal & suficiente para & entre as estratégias \\
& do empreendi- & garantir o fluxo de & trabalhadas. \\
& mento. & clientes. & \\
\hline & & & \\
& & & \\
& & & \\
& & & \\
& & &
\end{tabular}




\begin{tabular}{|c|c|c|c|}
\hline $\begin{array}{l}\text { Sugestão da } \\
\text { equipe: }\end{array}$ & $\begin{array}{l}\text { Sugestão da } \\
\text { equipe: }\end{array}$ & $\begin{array}{l}\text { Sugestão da } \\
\text { equipe: }\end{array}$ & $\begin{array}{l}\text { Sugestão da } \\
\text { equipe: }\end{array}$ \\
\hline $\begin{array}{l}\text { Como estratégia, } \\
\text { sugere-se verificar } \\
\text { a possibilidade de } \\
\text { preços mais baixos } \\
\text { junto ao fornece- } \\
\text { dor, sem interferir } \\
\text { na qualidade dos } \\
\text { produtos. A cria- } \\
\text { ção de combos } \\
\text { econômicos de } \\
\text { bebida e hambúr- } \\
\text { guer dos produtos } \\
\text { com menor saída } \\
\text { pode ser uma } \\
\text { alternativa. Além } \\
\text { disso, aperfeiçoar } \\
\text { os processos na } \\
\text { elaboração dos } \\
\text { pratos para que } \\
\text { haja economia de } \\
\text { água e energia, } \\
\text { entre outros. }\end{array}$ & $\begin{array}{l}\text { É preciso verifi- } \\
\text { car se o ponto do } \\
\text { negócio continua } \\
\text { sendo um bom } \\
\text { local de circula- } \\
\text { ção de potenciais } \\
\text { clientes e fazer } \\
\text { uma análise da } \\
\text { concorrência, } \\
\text { saber seus diferen- } \\
\text { ciais, bem como } \\
\text { seus pontos fracos } \\
\text { para potencializar } \\
\text { o negócio. Este } \\
\text { objetivo pode ser } \\
\text { alcançado por } \\
\text { meio de uma pes- } \\
\text { quisa de satisfação } \\
\text { com os consumi- } \\
\text { dores da casa. }\end{array}$ & $\begin{array}{l}\text { Sugere-se uma } \\
\text { pesquisa de mer- } \\
\text { cado com foco } \\
\text { na concorrência } \\
\text { para verificar se o } \\
\text { cardápio está ade- } \\
\text { quado à preferên- } \\
\text { cia do público na } \\
\text { cidade e também } \\
\text { para descobrir } \\
\text { quais novos sa- } \\
\text { bores podem ser } \\
\text { incorporados ao } \\
\text { menu. Uma aná- } \\
\text { lise dos produtos } \\
\text { que não têm gran- } \\
\text { de saída também } \\
\text { se faz necessária } \\
\text { para trabalhar es- } \\
\text { trategicamente ou, } \\
\text { até mesmo, tirá- } \\
\text {-los do cardápio. }\end{array}$ & $\begin{array}{l}\text { Para atrair novos } \\
\text { clientes, sugere-se } \\
\text { a criação de divul- } \\
\text { gação nos dois ca- } \\
\text { nais, seja por meio } \\
\text { de divulgação na } \\
\text { TV, na rádio, no } \\
\text { jornal, em out- } \\
\text { door e panfletos, } \\
\text { quanto por meio } \\
\text { digital, como Ins- } \\
\text { tagram, Snapchat, } \\
\text { Facebook e Twit- } \\
\text { ter. Nestes canais, } \\
\text { sugere-se divulga- } \\
\text { ção de promoções, } \\
\text { abordando dias de } \\
\text { semana com baixa } \\
\text { demanda no esta- } \\
\text { belecimento. Con- } \\
\text { siderando o públi- } \\
\text { co que frequenta } \\
\text { a hamburgueria, a } \\
\text { sugestão é investir } \\
\text { em canais diversi- } \\
\text { ficados, de forma } \\
\text { planejada e avaliar } \\
\text { periodicamente } \\
\text { os resultados al- } \\
\text { cançados em cada } \\
\text { meio. }\end{array}$ \\
\hline
\end{tabular}

Com base na análise e nas sugestões apresentadas anteriormente, seguem as principais contribuições como Plano de Ação a ser seguido pela Rock Hamburgueria (vide Quadro 3): 


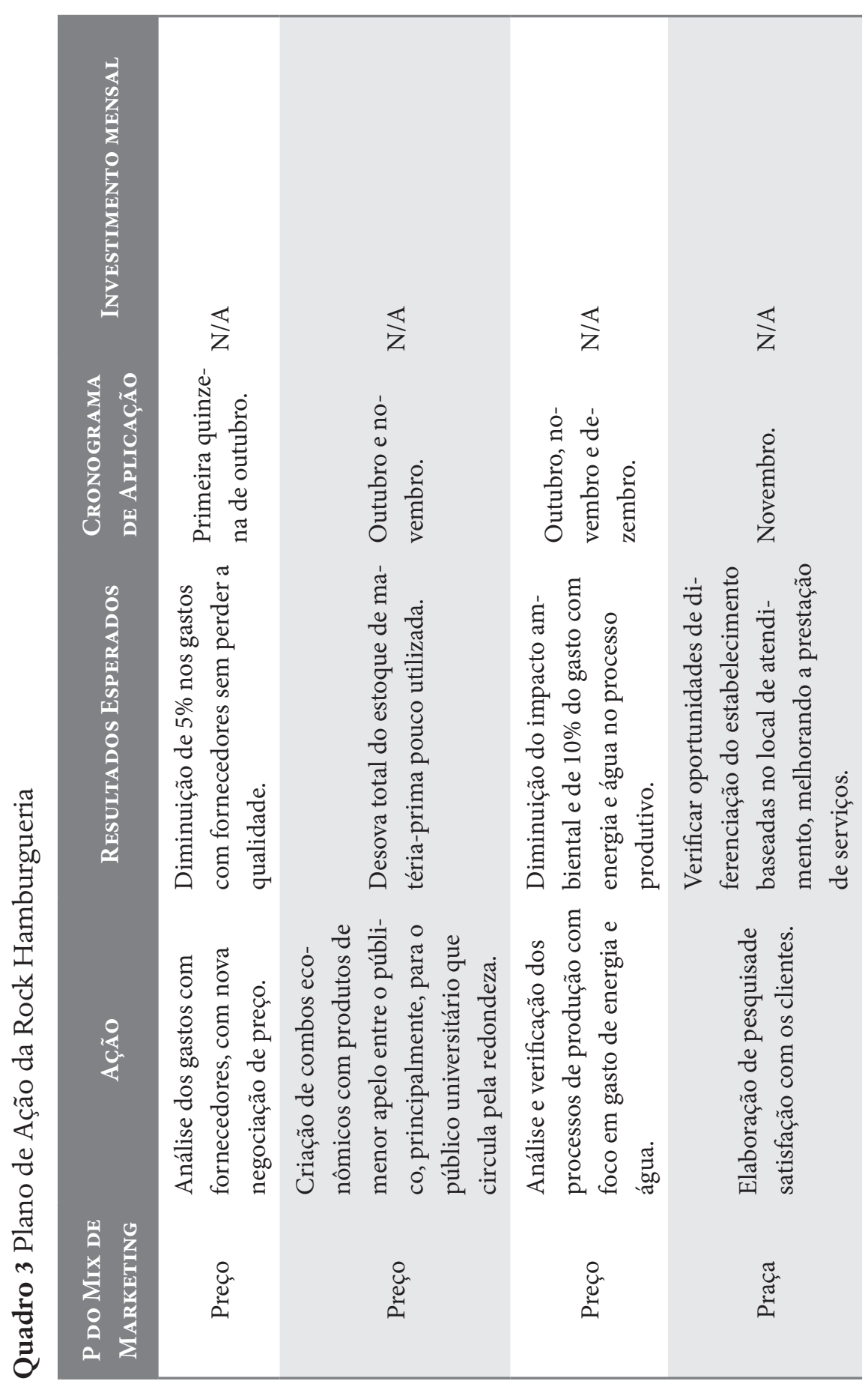



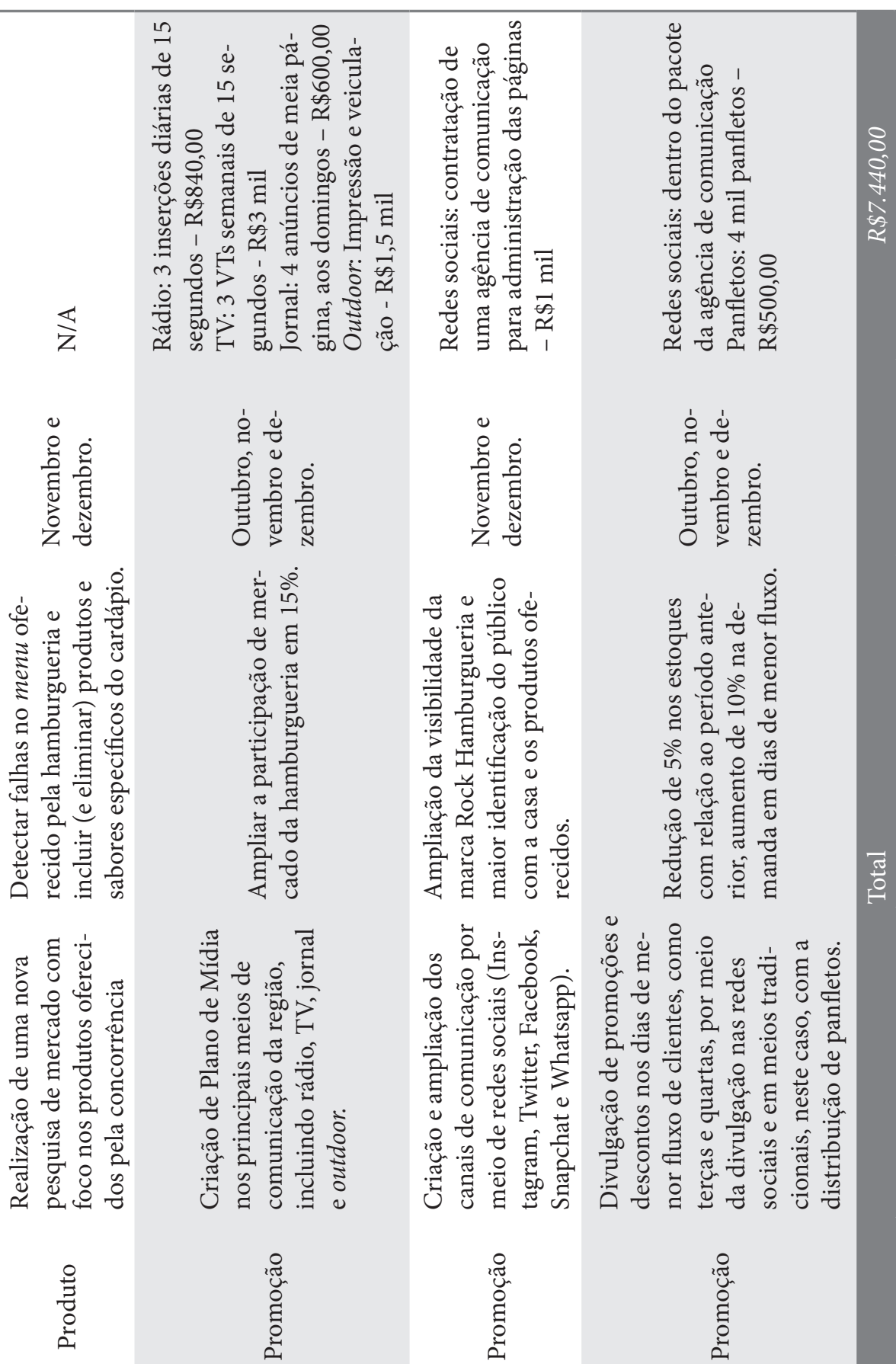
Sugere-se que os sócios sigam o Plano de Ação e, após o mês de dezembro, realizem nova análise dos resultados obtidos com a ação, com isso, visando transformar as mais bem-sucedidas em ações contínuas praticadas pelo empreendimento.

3. Quais ferramentas de marketing digital poderiam ser implantadas pela Rock Hamburgueria? E quais ferramentas de marketing tradicional poderiam ser utilizadas? De que forma essas ferramentas podem ampliar o número de clientes da empresa? Crie quadros dispondo essas informações e apresente projeções dos resultados. Considere um orçamento enxuto, de acordo com o porte da empresa.

Marketing tradicional: o marketing tradicional surge de um mercado com canais de distribuição genéricos e produtos padrões. Assim, a relação com os clientes acontece de forma indiferenciada por meio de meios de comunicação de massa (PINHO, 1999). Essas mídias de massa consistem em jornais, revistas, rádio, televisão e cartazes, desse modo, visando abranger a totalidade, ou seja, receptores não diferenciados (KOTLER, 1980).

O marketing tradicional é uma categoria bastante ampla, que incorpora muitas formas de publicidade e marketing. É o tipo mais reconhecível de marketing, que engloba anúncios que vemos e ouvimos todos os dias. A maioria das estratégias de marketing tradicionais é abrangida por uma das quatro categorias: impressão, transmissão, mala direta e telefone (MARKETING SCHOOLS, 2012), elas são apresentadas no quadro 4. 
Quadro 4 Categorias do Marketing Tradicional

\begin{tabular}{|cl|}
\hline Impresso & $\begin{array}{l}\text { Anúncios em jornais, boletins, revistas, } \\
\text { entre outros materiais impressos para } \\
\text { distribuição. }\end{array}$ \\
Transmissão & $\begin{array}{l}\text { Rádio e televisão comerciais, bem como } \\
\text { formas especializadas como a publicidade } \\
\text { na tela do cinema. }\end{array}$ \\
& $\begin{array}{l}\text { Folhetos, cartões postais, catálogos e outros } \\
\text { materiais que são impressos e enviados } \\
\text { diretamente aos consumidores. }\end{array}$ \\
Telemarketing & $\begin{array}{l}\text { Contato com os consumidores por meio do } \\
\text { telefone. }\end{array}$ \\
\hline
\end{tabular}

O marketing tradicional foi inventado para mercados e indústrias estáticas, em uma era de artigos produzidos em série. Ao contrário da abordagem do marketing digital, o marketing tradicional enfatiza a promoção de produtos e a difusão de informações e compreende maior veiculação de anúncios e emissão de comunicados à imprensa (MCKENNA, 1989). Apesar das mudanças ocorridas, o marketing de massa sempre será essencial a fim de atender demandas que o database marketing e o marketing direto não consigam vislumbrar (HYGHES, 1998).

Como abrange diferentes estratégias, as empresas que querem promover um produto ou serviço utilizam um ou mais tipos de marketing tradicional como parte de uma estratégia global de publicidade. Sua escolha está ligada diretamente ao orçamento de marketing disponível (MARKETING SCHOOLS, 2012). Com relação ao caso da Rock Hamburgueria, que apostou no boca a boca, Klapper (1960) indica que a influência pessoal pode ser mais eficiente do que a comunicação persuasiva de massa, no entanto a comunicação de massa é um meio eficiente de estimular a influência pessoal (vide Quadro 5). 
Quadro 5 Estratégias de Marketing Tradicional para a Rock Hamburgueria

\begin{tabular}{|c|c|c|c|}
\hline MÍdIA & Aç̃̃o & ProJeÇÃo & $\begin{array}{c}\text { INVESTIMENTO } \\
\text { MENSAL }\end{array}$ \\
\hline Jornal & $\begin{array}{l}\text { Veiculação de } 24 \text { anúncios } \\
\text { coloridos no jornal local, dis- } \\
\text { tribuídos em três vezes por } \\
\text { semana (quarta, sexta e do- } \\
\text { mingo), durante } 8 \text { semanas, } 1 / 4 \\
\text { de página. }\end{array}$ & $\begin{array}{l}\text { Aumento de } 10 \% \text { nas } \\
\text { vendas nos dias de } \\
\text { circulação do jornal } \\
\text { com anúncio da } \\
\text { Rock Hamburgueria. }\end{array}$ & $\mathrm{R} \$ 2$ mil \\
\hline Rádio & $\begin{array}{l}\text { Patrocínio de um programa } \\
\text { voltado para o público jovem, } \\
\text { com a divulgação de promo- } \\
\text { ções especiais e integração } \\
\text { com as redes sociais, aos } \\
\text { sábados à tarde, durante } 4 \\
\text { semanas. }\end{array}$ & $\begin{array}{l}\text { Aumento de } 15 \% \\
\text { da participação dos } \\
\text { ouvintes nas promo- } \\
\text { ções da hamburgue- } \\
\text { ria vinculadas com as } \\
\text { redes sociais. }\end{array}$ & $\mathrm{R} \$ 1 \mathrm{mil}$ \\
\hline Panfletos & $\begin{array}{l}\text { Distribuição de } 3 \text { mil panfletos } \\
\text { pelos bairros próximos e pelas } \\
\text { proximidades da universidade. }\end{array}$ & $\begin{array}{l}\text { Aumento de } 10 \% \text { dos } \\
\text { clientes oriundos do } \\
\text { bairro e localidades } \\
\text { próximas, e dos aca- } \\
\text { dêmicos. }\end{array}$ & $\mathrm{R} \$ 350,00$ \\
\hline Televisão & $\begin{array}{l}\text { Quatro inserções de } 30 \text { segun- } \\
\text { dos, durante o intervalo do } \\
\text { jornal local do meio-dia. }\end{array}$ & $\begin{array}{l}\text { Aumento de } 30 \% \\
\text { dos clientes oriundos } \\
\text { de outros bairros da } \\
\text { cidade e região. }\end{array}$ & $\mathrm{R} \$ 2$ mil \\
\hline Outdoor & $\begin{array}{l}\text { Um outdoor divulgando o } \\
\text { hambúrguer mais vendido da } \\
\text { Rock Hamburgueria, em pon- } \\
\text { to estratégico, na rua que dá } \\
\text { acesso à universidade próxima } \\
\text { ao empreendimento. }\end{array}$ & $\begin{array}{l}\text { Ampliação da lem- } \\
\text { brança da marca } \\
\text { pelos pedestres e } \\
\text { motoristas do bairro } \\
\text { de instalação do esta- } \\
\text { belecimento. }\end{array}$ & $\mathrm{R} \$ 1,5 \mathrm{mil}$ \\
\hline \multicolumn{3}{|c|}{ Total } & $\mathrm{R} \$ 6.850,00$ \\
\hline
\end{tabular}


Marketing Digital: o marketing digital é definido como o processo de construção e manutenção de relações com consumidores, por meio de atividades on-line, para facilitar o intercâmbio de ideias, produtos e serviços que satisfaçam os objetivos de ambas as partes (MOHAMMED et al., 2003). Segundo Ryan (2014), ao contrário dos meios convencionais de comunicação, a internet é única em sua capacidade, tanto em ampliar o seu alcance de marketing quanto, ao mesmo tempo, em estreitar seu foco.

Tanto a internet quanto os celulares trouxeram a oportunidade de segmentação e aumentaram a responsabilidade das ações de marketing (MOHAMMED et al., 2003). Ademais, o meio digital permite a personalização e interatividade em diversos níveis, com custos menores se comparados aos dos meios tradicionais (REDANT, 2014).

Nas pequenas empresas e nos novos empreendimentos, a atividade de planejamento de marketing recebe pouca atenção. As operações de marketing estão predominantemente relacionadas ao gerenciamento de crises (CARSON, 1990). Considerando esses fatores relacionados ao marketing digital e a importância de um planejamento estratégico, surgem algumas opções para a divulgação da Rock Hamburgueria nas redes sociais por seus empreendedores. O objetivo é, além da divulgação da empresa, estabelecer, mormente, um canal de relacionamento com os clientes, conforme apresentado no quadro 6 . 
Quadro 6 Estratégias de Marketing Digital para a Rock Hamburgueria

\begin{tabular}{|c|c|c|}
\hline $\begin{array}{l}\text { REDE } \\
\text { Social }\end{array}$ & Aç̃̃o & ProjeçÃo (3 MESEs) \\
\hline Facebook & $\begin{array}{l}\text { Divulgação de material } \\
\text { promocional para os clientes, } \\
\text { como ofertas relâmpago. } \\
\text { Postagens especiais em datas } \\
\text { comemorativas. } \\
\text { Postagens para divulgação de } \\
\text { novos pratos. }\end{array}$ & $\begin{array}{l}\text { Obtenção de } 600 \text { novos } \\
\text { seguidores. } \\
\text { Interação com os clientes } \\
\text { por meio de um post } \\
\text { por dia. }\end{array}$ \\
\hline Instagram & $\begin{array}{l}\text { Divulgação de fotografias pro- } \\
\text { duzidas especialmente para a } \\
\text { rede social, principalmente, dos } \\
\text { hambúrgueres, destacando a } \\
\text { qualidade do prato. } \\
\text { Uso de hashtags e convite para } \\
\text { interação com o público. }\end{array}$ & $\begin{array}{l}\text { Três postagens por } \\
\text { semana, com mínimo de } \\
50 \text { likes/cada. } \\
\text { Disseminação das } \\
\text { hashtags relacionadas à } \\
\text { marca. }\end{array}$ \\
\hline Twitter & $\begin{array}{l}\text { Promoções com hashtags } \\
\text { especiais em fins de semana, } \\
\text { utilizando o humor para } \\
\text { engajar seguidores. }\end{array}$ & $\begin{array}{l}\text { Obtenção de } 300 \\
\text { seguidores ao final do } \\
\text { período. }\end{array}$ \\
\hline WhatsApp & $\begin{array}{l}\text { Inclusão de serviço de entrega } \\
\text { pelo aplicativo. }\end{array}$ & $\begin{array}{l}\text { Mínimo de cinco } \\
\text { pedidos/dia via aplicativo } \\
\text { ao fim do período. }\end{array}$ \\
\hline Snapchat & $\begin{array}{l}\text { Divulgação de vídeos sobre a } \\
\text { preparação dos pratos e convite } \\
\text { para os clientes aproveitarem as } \\
\text { promoções disponíveis. }\end{array}$ & $\begin{array}{l}\text { Cinco vídeos por } \\
\text { semana, concentrando-se } \\
\text { na sexta-feira ao fim da } \\
\text { tarde e no sábado à noite. }\end{array}$ \\
\hline Investimento & \multicolumn{2}{|c|}{$\begin{array}{l}\text { Contratação de Agência de Comunicação para produção de } \\
\text { conteúdo e administração das páginas das redes sociais - } \\
\text { Pacote Premium - R } \$ 1,8 \text { mil por } 3 \text { meses = R } \$ 5.400,00\end{array}$} \\
\hline
\end{tabular}




\section{SEMELHANÇAS E DIFERENÇAS}

As estratégias (tanto tradicional quanto digital) são as mesmas: segmentar o mercado, entender o cliente e posicionar-se por meio de grandes histórias. No entanto há grandes diferenças, principalmente, no que concerne à velocidade da informação, que é muito mais rápida no marketing digital e na mensuração dos resultados de investimento, muito mais fácil e precisa no ambiente on-line (DIGITAL MARKETING STRATEGY, 2016).

Para as empresas de hoje, é imperativo ter um site e usar a web como meio de interagir com sua base de consumidores. Todavia existem algumas estratégias tradicionais de marketing que são interessantes, especialmente, se o objetivo é atingir um público local. Como se percebe, ambas as estratégias de marketing revelam funcionalidades e são úteis para as empresas na captação, na manutenção e no relacionamento com o cliente.

Enquanto o marketing tradicional envolve grande audiência, principalmente, local, tem dificuldade de mensuração, alto custo de investimento, pouca interatividade e audiência segmentada pelas características de cada meio, o marketing digital conta com audiência ilimitada (local ou global), é de fácil mensuração, exige baixo custo de investimento, é extremamente interativo e apresenta resultados instantâneos.

\section{No contexto de estratégias de marketing, como os sócios podem utili- zar o marketing de relacionamento para atingir este objetivo? Apresente a teoria relacionada, embasando suas sugestões de estratégias.}

Como gestores, André e Melissa têm dois grandes desafios pela frente: conquistar novos clientes e atrair clientes antigos em meio a um cenário de aumento da concorrência e reduzido capital para financiamento de estratégias de marketing. Para atingir esses objetivos, o marketing de relacionamento surge como alternativa para os problemas de demanda da Rock Hamburgueria.

Day, Dean e Reynolds (1998) argumentam que o marketing de relacionamento auxilia e contribui para maiores taxas de crescimento do negócio, paralelamente com a redução da perda de clientes, ou seja, é uma estratégia 
que maximiza tanto a demanda real quanto potencial referente aos clientes que desejam o produto e que detêm as condições financeiras para adquiri-lo. McKenna (1993) também contribui de forma esclarecedora acerca do Marketing de Relacionamento, para tanto, refere que deve apoiar-se no conhecimento e na experiência, enfatizando a interatividade, a conectividade e a criatividade. Por meio dessa abordagem, as organizações dedicam-se aos seus clientes, monitoram seus concorrentes de forma constante e desenvolvem um sistema de análise de feedback que transforma essa informação sobre mercado e concorrência em uma nova informação sobre o produto. As ações ligadas ao relacionamento em marketing subdividem-se em cinco processos, segundo Ribeiro (1997 apud RIBEIRO; GRISI; SALIBY, 1999):

- Canal com o cliente (feedback): análise dos padrões de feedback e dos históricos de compras; implantação de hotline, sistemas de atendimento ao consumidor; análise dos e-mails dos clientes; pesquisas formais e informais.

- Especialização na base de clientes: por meio de programas de fidelidade, de afinidade, de aumento de volume de vendas, tais como cross-selling (venda cruzada) ou upgrade (intensificação do volume, valor ou frequência da compra).

- Nichos de mercado com eficiência e lucro: a partir das informações no banco de dados, é possível encontrar nichos de mercado e viabilizar a atuação nesses, vencendo a barreira do tamanho do mercado e da perda de economia de escala.

- Maior controle do canal de distribuição: oferecendo melhores informações sobre o público-alvo e permitindo melhor adequação da oferta.

- Melhor contabilização do marketing: aumento na capacidade de mensurabilidade do sistema e da capacidade de controle das variáveis que influenciam as respostas.

Assim, considerando esses aspectos levantados, André e Melissa podem implantar diversas estratégias de Marketing de Relacionamento para ampliar o alcance de seu empreendimento. No Quadro 7 são apresentadas algumas ações a serem implantadas baseadas na teoria: 
Quadro 7 Marketing de Relacionamento aplicado à Rock Hamburgueria

\begin{tabular}{|c|c|}
\hline Processo & AÇão \\
\hline Canal com o Cliente & $\begin{array}{l}\text { Pesquisa de satisfação com os clientes. } \\
\text { Criação de canal para sugestões na fanpage do } \\
\text { Facebook. } \\
\text { Verificação de feedbacks em sites de review como } \\
\text { Reclame Aqui, Foursquare e Tripadvisor. Além } \\
\text { do monitoramento dos comentários expostos } \\
\text { nas redes sociais como Twitter e Facebook. }\end{array}$ \\
\hline $\begin{array}{c}\text { Especialização na Base } \\
\text { de Clientes }\end{array}$ & $\begin{array}{l}\text { Criação de programa de fidelidade com } \\
\text { descontos a partir da compra de cinco } \\
\text { lanches/cliente, gerando aumento no volume } \\
\text { de compra. }\end{array}$ \\
\hline $\begin{array}{l}\text { Nichos de Mercado com } \\
\text { Eficiência e Lucro }\end{array}$ & $\begin{array}{l}\text { Criação de estratégias para os públicos-alvo do } \\
\text { estabelecimento (ex: happy hour para jovens } \\
\text { com cerveja em dobro, menu kids para que } \\
\text { as famílias possam economizar com os filhos } \\
\text { pequenos). }\end{array}$ \\
\hline $\begin{array}{l}\text { Maior Controle do } \\
\text { Canal de Distribuição }\end{array}$ & $\begin{array}{l}\text { Cruzamento de informações sobre o público- } \\
\text {-alvo a partir da pesquisa de satisfação e do } \\
\text { sistema utilizado no caixa, levando em consi- } \\
\text { deração fatores como idade, local de moradia, } \\
\text { sexo e expectativas com o produto, de modo a } \\
\text { utilizar as informações como um ativo na co- } \\
\text { municação entre empresa x clientes. }\end{array}$ \\
\hline $\begin{array}{l}\text { Melhor Contabilização } \\
\text { do Marketing }\end{array}$ & $\begin{array}{l}\text { Utilização de ferramentas de tracking de tráfego } \\
\text { de informações nas redes sociais para mensura- } \\
\text { ção dos resultados, fortalecendo as estratégias } \\
\text { de relacionamento. } \\
\text { Desenvolvimento de pesquisa com os } \\
\text { clientes para descobrir quais são os meios de } \\
\text { comunicação que estão sendo mais eficientes na } \\
\text { divulgação. }\end{array}$ \\
\hline
\end{tabular}


Acredita-se que, a partir da utilização de estratégias de marketing de relacionamento em complemento com outras ações da área, como o uso adequado do marketing tradicional e digital pela empresa, os sócios conseguirão atingir resultados positivos e ampliar o faturamento da Rock Hamburgueria. 


\section{REFERÊNCIAS}

CARSON, D. Some Exploratory Models for Assessing Small Firms\# Marketing Performance (A Qualitative Approach). European Journal of Marketing, v. 1., n. 24, p. 8-51, 1990.

CHURCHILL, G. A. J.; PETER, J. P. Marketing: criando valor para os clientes. 2 ed. São Paulo: Saraiva, 2005.

DAY, J.; DEAN, A. A.; REYNOLDS, P. L. Relationship Marketing: Its Key Role in Entrepreneurship. Long Range Planning, v. 31, n. 6, p. 828-837, 1998.

DIGITAL MARKETING STRATEGY. Digital Marketing vs. Traditional Marketing. Disponível em: <http:/ / digital-marketing-strategy.weebly.com/digital-marketing.html> . Acesso em 27/04/2016.

DRUCKER, P. F. Administração: Responsabilidades, Tarefas, Práticas. São Paulo: Pioneira, 1975.

DRUCKER, P. F. Innovation and entrepreneurship. New York: Harper \& Row, 1985.

FOLHA UOL. Hamburguerias viram hit em SP e número de casas gourmet cresce 500\%. Publicado em 2014.

HONORATO, G. Conhecendo o Marketing. São Paulo: Manole, 2003.

HYGHES, A.M. Database Marketing Estratégico. São Paulo: Makron, 1998.

KLAPPER, J.T. The effects of Mass Comunication. New York: The Free Press, 1960. KOTLER, P. Marketing. São Paulo: Atlas, 1980.

LUTHANS, F. Environmental and Psychological Challenges Facing Entrepreneurial Development in Trasitional Economies. Journal of World Business, v. 35, p. 95-110, 2000.

MARKETING SCHOOLS. Traditional Marketing: Explore the Strategy of Traditional Marketing. 2012. Disponível em < http:/ / www.marketing-schools.org/types-of-marketing/traditional-marketing.html>. Acesso em: 27/04/2015.

MCKENNA, R. Estratégias de marketing em tempos de crise. Rio de Janeiro: Campus, 1989.

MCKENNA, R. Marketing de relacionamento: estratégias bem-sucedidas para a era do cliente. Rio de Janeiro: Campus, 1993.

MORRIS, M. H.; PAUL, G. W. The Relationship between Entrepreneurship and Marketing in Established Firms. Journal of Business Venturing, v. 2, p. 247-259, 1987.

MOHAMMED, R. A. et al. Internet Marketing - Building Advantage in the Networked Economy. Singapore: McGraw-Hill Companies, Inc, 2003. 
PINHO P. Marketing na Internet: da evolução do conceito ao marketing mix. Revista Portuguesa de Marketing, v. 2, n. 7, p. 87-97, 1999.

REDANT. Planning and Managing Digital Strategy. England \& Wales: Creative Commons, 2014.

RIBEIRO, A. H. P.; GRISI, C. C. H.; SALIBY, P. E. Marketing de Relacionamento como fator-chave de sucesso no mercado de seguros. Revista de Administração de Empresas, v. 39, n. 1, p. 31-41, 1999.

RYAN, D. Understanding Digital Marketing. Grã-Bretanha: Kogan Page, 2014.

SCHINDEHUTTE, M.; MORRIS, M. H. Understanding strategic adaptation in small firms. International Journal of Entrepreneurial Behavior \& Research, v. 7, n. 3, p. 84107, 2001.

SEBRAE - Serviço Brasileiro de Apoio às Micro e Pequenas Empresas. Pesquisa GEM 2014. Disponível em: <http://www.sebrae.com.br/sites/PortalSebrae/estudos_pesquisas/Pesquisa-GEM:-empreendedorismo-no-Brasil-e-no-mundo, destaque,9>. Acesso em: $02 / 10 / 2015$. 


\section{DADOS DOS AUTORES}

\section{ANA PAULA KIELING`anakieling@gmail.com}

Mestre em Administração com ênfase em Marketing pela UFSC

Instituição de vinculação: Universidade do Vale do Itajaí

Biguaçu/SC - Brasil

Áreas de interesse em pesquisa: Marketing e Comportamento do Consumidor.

* Rua João Coan, 400 Universitário Biguaçu/SC 88161-064

\section{ESTELA MARIA HOFFMANN estelamhoff@gmail.com}

Mestre em Administração com ênfase em Marketing pela UNIVALI

Instituição de vinculação: Universidade do Vale do Itajaí

Biguaçu/SC - Brasil

Áreas de interesse em pesquisa: Marketing e Comportamento do Consumidor.

\section{RICARDO BOEING ricardo.boeing@uspw.edu}

Doutor em Administração com ênfase em Marketing pela FGV-EAESP

Instituição de vinculação: University of Wisconsin - Stevens Point

Stevens Point/Wisconsin - Estados Unidos

Áreas de interesse em pesquisa: Marketing e Comportamento do Consumidor. 